\title{
The Silica Minerals
}

Quartz Family Minerals

A Handbook for the Mineral Collector. By H. C. Dake, Frank L. Fleener and Ben Hur Wilson. Pp. xvi+304. (New York and London: McGrawHill Book Co., Inc., 1938.) 12s. $6 d$.

IN an age when thousands of books are published I annually, covering almost every subject, it seems remarkable that so few have been written to introduce the general reader to the wonder and beauty of the mineral kingdom. In the United States some attempts have recently been made to fill this gap in the literature-an outstanding example being "Getting Acquainted with Minerals" by G. L. English. The present work is of the same persuasive kind, and though limited in its field to the silica minerals, serves also as an introduction to general mineralogy.

Like so many other of the common minerals, quartz possesses properties of the deepest scientific interest and furnishes problems, many of which still remain unsolved. Moreover, since some $60 \mathrm{per}$ cent of the lithosphere consists of silica, a great part of which is in an uncombined state, ample material for first-hand study can be gathered by the collector in almost any part of the world, or can be purchased cheaply from a mineral dealer. "Quartz Family Minerals" opens with an explanation of the importance of quartz and a brief survey of its use in past ages. After two excellent chapters, in which the authors discuss the various conditions which led to the deposition of silica minerals in the rocks, a description is given of the quartz crystal habit and of the various types of quartzcrystalline, crypto-crystalline and amorphous.

There is a long chapter on agate; theories of the manner of its growth are discussed and prescriptions given for producing banded, agate-like precipitates in suitable gelatin media on the Liesegang ring principle. Chapters on opal and on petrified forests complete the descriptive part of the book.

Naturally enough, in a work intended for American readers, the localities quoted for each variety of mineral are preponderantly American. Thus in the section on sand-filled calcites no mention is made of the curious sand-calcite rhombohedra found at Fontainebleau, so well known to the European mineralogist. The beautiful Mexican 'water opal' is not described, and quartz cat's-eye is dismissed in a single short sentence. The last twenty pages of the book deal with "The Art of Cutting Gem Quartz". In an appendix is given a selected bibliography of books and articles on the silica minerals and precious stones generally, in which the standard British work, G. F: Herbert Smith's "Gemstones" and Liesegang's classic, "Die Achate", should have been included.

Numerous misprints, and one or two factual errors, will need correction in future editions. On p. 36 it is stated that "the purest quartz (rock crystal) has a specific gravity of $2 \cdot 69$ " whereas the correct figure is $2 \cdot 654$; and on p. 176 fused quartz imitations of amethyst, etc. are said to have the "identical hardness and specific gravity" of the natural gem, which is by no means true.

Much interesting material, gathered from widely scattered sources, is collected together in the book, and it is well illustrated; it can be read with profit not only by the beginner but also by the more advanced mineralogist. $\quad$ B. W. A.

\section{Applications of Ultrasonics}

Ultrasonics and their Scientific and Technical Applications.

By Prof. Dr. Ludwig Bergmann. Translated by Dr. H. Stafford Hatfield. Pp. ix +264. (London : G. Bell and Sons, Ltd., 1938.) 16s. net.

$\mathrm{T}$ HE scientific study of ultrasonics, or the properties of high-frequency inaudible mechanical vibrations, may be said to date from the year 1883, when Galton published his book "Enquiries into Human Faculty". In this book he described the construction of the Galton whistle, an instrument which, refined in some details, is used to this day by psychologists and physiologists for the production of sounds of high pitch. The subject remained of little more than academic interest until, during the Great War, Langevin devised the first practical apparatus for the transmission and reception under water of inaudible 'sound' signals. For this purpose, Langevin utilized (1) the discovery by the brothers J. and P. Curie of the piezo-electric properties of quartz, and (2) the methods of generating and detecting electric oscillations made possible by the invention of 